\title{
When will my baby go home?
}

\author{
Peter J Powell, Colin V E Powell, Sally Hollis, Michael J Robinson
}

\begin{abstract}
The length of stay of preterm babies discharged from a neonatal nursery was determined and the predictive value of perinatal factors on the duration of stay was assessed on 762 preterm Salford born babies admitted to Hope Hospital neonatal unit between April 1986 and November 1990 . The data were analysed using multiple logistical regression and forward stepwise regression analysis. Babies were discharged at a median (quartile range) postconceptional age of $36 \cdot 3(35 \cdot 3-37 \cdot 6)$ weeks. Seventeen factors were found to be strongly predictive of discharge date. The most significant predictive factor was gestational age accounting for $40 \%$ of variability compared with respiratory difficulties $(6 \%)$, low birth weight $(4 \%)$, sepsis $(2 \%)$, and metabolic problems (1\%).

Most babies are discharged at approximately the same postconceptional age despite variations in their clinical course. Gestational age at birth is the most powerful predictive factor of time of discharge.
\end{abstract}

(Arch Dis Child 1992;67:1214-6)

When the initial shock accompanying the birth of a preterm baby has passed one of the first questions asked is 'when will my baby go home?' In an attempt to answer this question and to determine the predictive value of perinatal factors we have analysed computerised data relating to Salford born babies between April 1986 and November 1990. There is little published information to help paediatricians. Although many studies report outcome in terms of morbidity and mortality in relation to gestational age, ${ }^{1-5}$ only rarely is the postconceptional age at discharge also described. ${ }^{3} 67$ This has varied between 36-40 weeks' postconceptional age with average discharge weights of 2010-2627 g. These studies have reported the information for a discrete group of infants, for example all with birth weight less than 2000 g. ${ }^{6}$

Nothing is lost by discharging babies as soon as they are feeding well orally rather than by waiting for an arbitrary weight to be reached, ${ }^{8-10}$ and this has been local policy for the past 10 years. Hope Hospital provides a service to Salford, a socially disadvantaged district of the Greater Manchester conurbation with $44 \%$ of births to unmarried or unsupported women (England and Wales,
$28 \%, 1990$ ) and $8 \%$ low birthweight infants (England and Wales 6.7\% 1990). ${ }^{1}$

\section{Methods}

A computerised database of all babies requiring intensive or special care admitted to Hope Hospital from April 1986 has been kept. All data of inborn preterm survivors were stored prospectively on a Tandon IBM compatible computer. The records were checked for accuracy by two doctors and a medical secretary before manual data entry.

Gestational age was assessed by a combination of mother's dates, an ultrasound scan performed before 18 weeks' gestation, clinical assessment of the baby by the formula of Dubowitz et $a l^{12}$ and when appropriate by examination of the anterior vascular lens capsule. ${ }^{13}$ Gestation was thus entered to the nearest week. Records were abstracted from the database using the SCIMS operating system (Special Care Information Management System, Time Computers Ltd, Blackburn) and were analysed using the Statistical Package for Social Sciences. ${ }^{14}$ A multiple logistical regression model was used to assess the relative importance of maternal, pregnancy, birth, and infant factors on the

\section{Table 1 Details of infants studied}

\begin{tabular}{|c|c|c|c|}
\hline & Median & $\begin{array}{l}\text { Lower } \\
\text { quartile }\end{array}$ & $\begin{array}{l}\text { Upper } \\
\text { quartile }\end{array}$ \\
\hline $\begin{array}{l}\text { Gestational age at birth } \\
\quad \text { (weeks) } \\
\text { Birth weight (g) } \\
\text { Discharge weight (g) } \\
\text { Total days stay }\end{array}$ & $\begin{array}{l}34 \\
2146 \\
2261 \\
15\end{array}$ & $\begin{array}{l}33 \\
1714 \\
2020 \\
5\end{array}$ & $\begin{array}{l}36 \\
2460 \\
2544 \\
24\end{array}$ \\
\hline $\begin{array}{l}\text { Postconceptional age at } \\
\text { discharge (weeks) }\end{array}$ & $36 \cdot 3$ & $35 \cdot 3$ & $37 \cdot 6$ \\
\hline
\end{tabular}

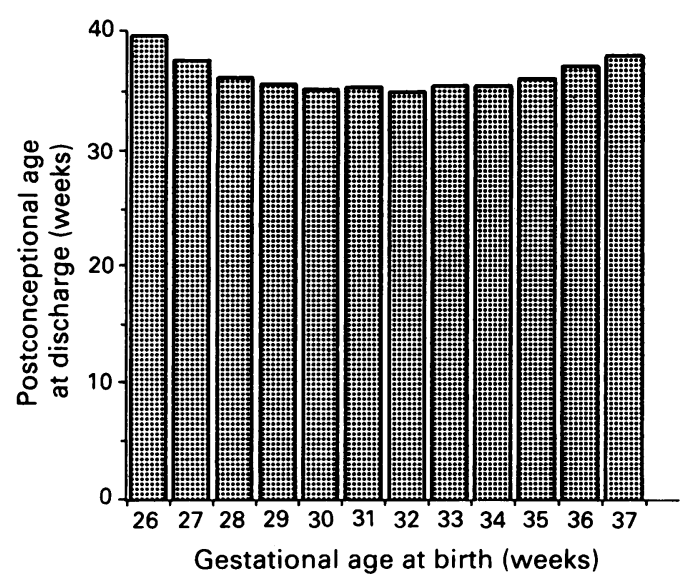

Figure 1 Postconceptional age at discharge and gestational age at birth. 
Table 2 Postconceptional age at discharge and gestational age at birth

\begin{tabular}{llll}
\hline $\begin{array}{l}\text { Gestational age } \\
\text { at birth (weeks) }\end{array}$ & $\begin{array}{l}\text { Postconceptional age } \\
\text { at discharge (weeks) }\end{array}$ & $\begin{array}{l}\text { Geometric mean } \\
\text { length of stay (days) }\end{array}$ & $\begin{array}{l}95 \% \text { Confidence } \\
\text { intervals* }\end{array}$ \\
\hline 24 & $41 \cdot 6$ & 123 & \\
25 & $40 \cdot 6$ & 109 & 77 to 117 \\
26 & $39 \cdot 6$ & 95 & 58 to 94 \\
27 & $37 \cdot 5$ & 74 & 49 to 65 \\
28 & $36 \cdot 1$ & 57 & 39 to 53 \\
29 & $35 \cdot 5$ & 45 & 30 to 42 \\
30 & $35 \cdot 1$ & 36 & 23 to 37 \\
31 & $35 \cdot 2$ & 29 & 17 to 24 \\
32 & $34 \cdot 9$ & 20 & 14 to 19 \\
33 & $35 \cdot 3$ & 16 & 7 to 10 \\
34 & $35 \cdot 2$ & 9 & 5 to 8 \\
35 & $35 \cdot 9$ & 7 & 5 to 8 \\
36 & $36 \cdot 9$ & 6 & 4 to 6 \\
37 & $37 \cdot 7$ & 5 & \\
\hline
\end{tabular}

*To nearest whole day. charge weight was 2261 (2020-2544) g. Median gestational age at birth was 34 (33-36) weeks and postconceptional age at discharge $36 \cdot 3(35 \cdot 3-37 \cdot 6)$ weeks (table 1). Figure 1 shows mean duration of stay expressed in terms of postconceptional age at discharge for a given gestational age at birth (see also table 2). Median duration of stay was 15 (5-24) days. For babies weighing less than $1500 \mathrm{~g}$ the median stay was $44(28-66)$ days and for babies of birth weight less than 1000 g, 86 (65-102) days (table 3).

Seventeen factors were strongly predictive of duration of stay. These are shown in table 4. The categories of problems were defined as follows. Respiratory: the need for additional oxygen or artificial ventilation; neurological: the presence of fits, periventricular haemorrhage, periventricular leucomalacia, or structural central nervous system lesions; metabolic: hypernatraemia (sodium $>150 \mathrm{mmol} / \mathrm{l}$ ), hyponatraemia (sodium $<130 \mathrm{mmol} / \mathrm{l}$ ), hyperkalaemia (potassium $>7.0 \mathrm{mmol} / \mathrm{l}$ ), hypoglycaemia (glucose $<2.5 \mathrm{mmol} / \mathrm{l}$ ), or severe acidosis $(\mathrm{pH}<7 \cdot 1)$.

Forward stepwise regression analysis of these factors against duration of stay identified five which remained strongly predictive of discharge time. This type of analysis takes into account the interrelated nature of these perinatal events and prioritises the independent contribution of each to duration of stay. Gestational age was the most significant factor accounting for $40 \%$ of the variability and was related logarithmically to duration of stay (table 5 and fig 2).

There were 47 sets of twins in the study group, 41 of whom were discharged together. In six sets there was a delay before discharge of the second twin of seven to 19 days. Of the 41 sets discharged together there was a significant disparity of clinical course in 10 . The median difference in days of intensive care was 6.5 days $(p<0.02$ Wilcoxon signed rank sum test) for this group compared with 3.5 days for the six sets of twins discharged separately ( $p$ not significant for difference between groups).

\section{Discussion}

Most babies were discharged at approximately the same postconceptional age (36-37 weeks),

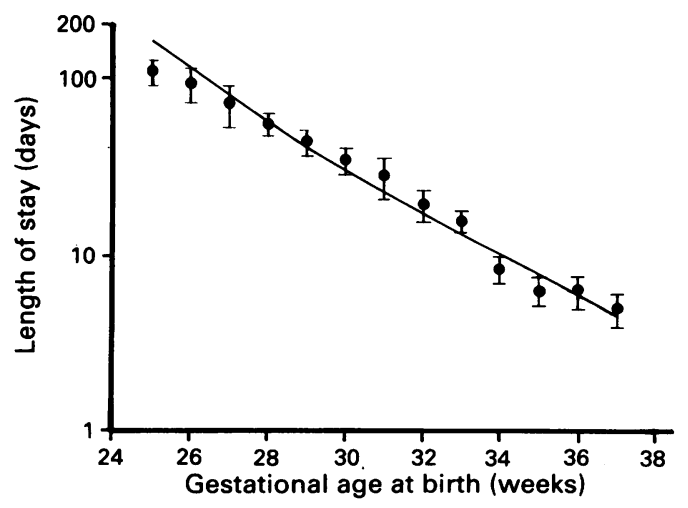

Figure 2 Predicted length of stay and gestational age at birth with geometric mean and $95 \%$ confidence intervals. 
Table 5 Analysis of factors that were strongly predictive of discharge date by forward stepwise regression

\begin{tabular}{lllll}
\hline Rank & Factor & $\begin{array}{l}\text { \% Variability of } \\
\text { discharge date } \\
\text { accounted for }\end{array}$ & $\begin{array}{l}\text { \% Cumulative } \\
\text { variability }\end{array}$ & p Value \\
\hline 1 & Gestational age & 39.7 & 39.7 & $<0.0001$ \\
2 & Respiratory problems & 6.5 & 46.2 & $<0.0001$ \\
3 & Birth weight (log) & $4 \cdot 4$ & 50.6 & $<0.0001$ \\
4 & Infections & $1 \cdot 8$ & 52.4 & $<0.0001$ \\
5 & Metabolic problems & 0.8 & 53.2 & $<0.0005$ \\
& All other factors & $<1.0$ & 56.6 & $>0.01$ \\
\hline
\end{tabular}

which is perhaps surprising in view of the variation of clinical course. We confirmed that babies of less than 29 weeks' gestation tended to be discharged later. ${ }^{7}$

The observed median discharge age in this study is earlier than that reported by Lequien et al (39 weeks) ${ }^{6}$ and $\mathrm{Yu}$ et al (40 weeks gestational age equivalent $)^{3}$ but comparable with Brooten et al (36 weeks). ${ }^{10}$ The apparent discrepancies are not great, however, when the populations of babies are compared. In the studies of Lequien et al and Yu et al the babies were born weighing less than $2000 \mathrm{~g}^{6}$ or below 27 weeks' gestation. ${ }^{3}$ However there was a significant difference between the observed duration of stay and that reported by Monset-Couchard et al in whose study the median stay was 69 days compared with 44 for very low birthweight babies and 109 days compared with 86 in Salford babies of less than $1000 \mathrm{~g}$ birth weight. ${ }^{7}$ This is unlikely to be due to differences in the proportions of light for dates babies. A higher median discharge weight of $2627 \mathrm{~g}$ (compared with 2261 $\mathrm{g}$ in Salford) was also reported in keeping with the longer duration of stay. The study of Ryan et al reporting an average stay of 48 days for babies weighing less than $1000 \mathrm{~g}$ includes deaths and is not comparable. ${ }^{15}$

The lower postconceptional age at discharge seen in Salford babies probably reflects the functional rather than structural discharge policy, ${ }^{8}$ which depends upon continuing home supervision by community special care midwives. ${ }^{16}$

The most powerful single predictive factor of length of stay was the gestational age. The logarithmic relationship with total days of stay implies that the problems encountered by the more premature baby do not increase in a linear way with earlier gestation at delivery. It appears to be exponentially more difficult to look after such a baby for every arithmetic decrease in gestation. However gestational age also subsumes most of the confounding delaying factors, namely the presence of neurological problems, the need for prolonged ventilation, or extremely low birth weight. Although these factors did have an independent influence on duration of stay in that light for dates babies with respiratory difficulties and septi- caemia were discharged a little later than those without these problems, the additional contribution to the variation in discharge date is small.

This fact is underlined by the twins in the study. Although there may be a bias to discharge twins on the same day for ease of parental visiting, only six out of 47 sets were discharged separately. These six showed a smaller variation in clinical course than the majority in whom differences of up to 19 days intensive care were noted.

Despite analysis of 31 perinatal factors, $43 \%$ of the variability in discharge date remains unexplained. It is likely that some of this variability will be related to a combination of genetic and socioeconomic factors. It was not possible to analyse these factors directly but examination of related variables namely age, parity, and a history of previous perinatal death demonstrated a contribution to duration of stay of less than $1 \%$.

A preterm baby of more than 28 weeks' gestation is likely to be discharged at approximately 36-37 weeks' postconceptional age irrespective of perinatal history. The postconceptional age at discharge of more preterm babies approaches term. Gestational age is the strongest predictor of discharge date.

1 Wariyar U, Richmond S, Hey EN. Pregnancy outcome at 24-31 weeks' gestation: mortality. Arch Dis Child 1989;64:670-7.

2 Herschel M, Kennedy JL, Kayne HL, Henry M, Cetrulo CL. Survival of infants born at 24-28 weeks' gestation. Obstet Gynecol 1982;60:154-8.

3 Yu VY, Bajuk B, Orgill AA, Astbury J. Viability of infants born at 24-26 weeks' gestation. Ann Acad Med Singapore 1985;14:563-71.

4 Pauline Verloove-Vanhorick S, Verwey RA, Brand R Bennebroek Gravenhorst J, Keirse MJNC, Ruys JH Neonatal mortality risk in relation to gestational age and birthweight. Lancet 1986;i:55-7.

5 Stewart AL, Reynolds EOR, Lipscombe AP. Outcome fo infants of very low birthweight: survey of world literature. Lancet 1981;i: 1038-41.

6 Lequien P, Zaoui C, Duquennoy C, et al. Discharge to the family milieu of low birth weight children. Analysis of an experience with 'early' discharge in a neonatology unit. Arch Fr Pediatr 1986;43:471-74.

7 Monset-Couchard M, Jaspar ML, de-Bethmann O, Relier JP. Costs of the initial care of babies with birthweight less than or equal to $1500 \mathrm{~g}$ in 1981. Arch Fr Pediat 1984;41:579-85.

8 Davies DP, Haxby V, Herbert S, McNeish AS. When should preterm babies be sent home from neonatal units? Lancet 1979;i:914-5.

9 LeFebre F, Veilleux A, Bard H. Early discharge of low birthweight infants. Arch Dis Child 1982;57:511-3.

10 Brooten D, Kumar S, Brown LP, et al. A randomised clinical trial of early hospital discharge and home follow-up of very low birthweight infants. N Engl $\mathcal{F}$ Med 1986;315 934-9.

11 North West Regional Healthy Authority. Maternities and infants in North West region. Manchester: North Wes Regional Healthy Authority, 1991.

12 Dubowitz LMS, Dubowitz V, Goldberg D. Clinical assessment of gestational age in the newborn infant. $f$ Pediat 1970;77:1

13 Hittner HM, Hirsch NJ, Rudolph AJ. Assessment of gestational age by examination of the anterior vascular capsule of the lens. $\mathcal{F}$ Pediatr 1977;91:455-8.

14 SPSS. SPSS-X users guide. 3rd Ed. Chicago: SPSS Inc, 1988.

15 Ryan S, Sics A, Congdon P. Cost of neonatal care. Arch Dis Child 1988;63:303-6.

16 Couriel JM, Davies P. Costs and benefits of a community special care baby service. $B M \mp$ 1988;296:1044-6. 